\title{
On Certain Aspects of Daily Variation of Geomagnetic Field at Low Latitudes
}

\author{
R. G. RAStogi ${ }^{1}$ and A. R. PATIL ${ }^{2}$ \\ ${ }^{1}$ CSIR Emeritus Professor, Physical Research Laboratory, Ahmedabad 380 009, India \\ ${ }^{2}$ Indian Institute of Geomagnetism, Bombay 400005 , India
}

(Received November 18, 1991; Revised May 27, 1992)

\begin{abstract}
The daily variations of horizontal component of geomagnetic field, $H$, at low latitudes show significant asymmetry during active solar years. After reaching a maximum value at or slightly before noon the $H$ field decreases to the nighttime base level rather slowly even after sunset. The effect is present during any of the seasons and at different longitude sectors. The maintenance of current after sunset is observed even in $\Delta H$ Trivandrum minus Alibag. The continuation of positive $\Delta H$ (TRD - ABG) after sunset is more prominent during disturbed than on quiet days. The midday peak of $\Delta H$ at equatorial station occurs later during local winter than during local summer months at different longitudes. The equatorial electrojet current is suggested to be due to combined effects of multitude of sources of electric fields having different daily, seasonal and solar cycle variations.
\end{abstract}

\section{Introduction}

The daily variation of horizontal geomagnetic field $(H)$ at stations close to the magnetic equator has assumed increasingly greater importance in recent times. The unique condition of orthogonality of electric field, magnetic field and the plasma density gradient in the $E$ region over the magnetic equator makes this region very sensitive to the changes of the electric fields. The normal eastward electric field during the daytime causes a strong eastward current called equatorial electrojet. Besides, the atmospheric dynamo, other sources of electric fields at equatorial regions are due to action of solar wind with the interplanetary magnetic field reversals near the magnetopause (RASTOGI and PATEL, 1975), due to the penetration of high latitude electric fields to low latitudes (AKASOFU and CHAPMAN, 1963), due to regular magnetopause current (MEAD, 1964), due to symmetrical quiet time ring current (SCHIELD, 1969), due to partial ring current (KAVANAGH et al., 1968) and other magnetospheric processes. SARABHAI and NAIR (1971) have discussed various sources of magnetic field variations at low latitudes. OLSON (1989) has described the contributions of various magnetospheric currents to the $S q$ variations in different components of the geomagnetic fields observed at ground level. The isolation of regular and systematic deformations in the daily variations of the equatorial electrojet would help understanding of the relative importance of the various sources affecting the equatorial ionosphere.

RASTOGI and IYER (1976) found that the solar daily variation of $H$ at an equatorial station shows significant differences during low and high sunspot years. During low sunspot years, $H$ returns to the nighttime base level well before the sunset but during the high sunspot years the values of $H$ continue to decrease monotonously since noon upto hours beyond the sunset. 
The present article describes the daily variation of $H$ at equatorial and tropical latitude stations during different levels of solar activity specially about the asymmetrics in the daily variations and the continuation of ionospheric currents during the night time hours.

\section{Presentation of Data}

RASTOGI and IYER (1976) had compared the yearly mean daily variations of $H$ at low latitudes during the years 1959 to 1964 to show the abnormal features of the $S q$ variations. The post-sunset continuation of $\Delta H$ above the mid-night level was observed at both Trivandrum as well as Alibag. In Fig. 1 are shown $S q(H)$ variations at Huancayo and Trivandrum averaged for D months (November, December, January and February); E months (March, April, September and October) and J months (May, June, July and August) of the years of low (1964) and high (1958) solar activity. The post-sunset asymmetry in $\Delta H$ at Huancayo and Trivandrum was present during any of the seasons of the year of high sunspots, 1958.

Another interesting feature noticeable is that the largest amplitude of solar daily range of $H$ at Huancayo and Trivandrum occurs in equinoctial months. The daily range of $H$ at Huancayo was larger during $\mathrm{D}$ months than during the $\mathrm{J}$ months. The peak value of $\Delta H$ occurred earlier during D months (local summer) than during the J months (local winter). At Trivandrum, $\Delta H$

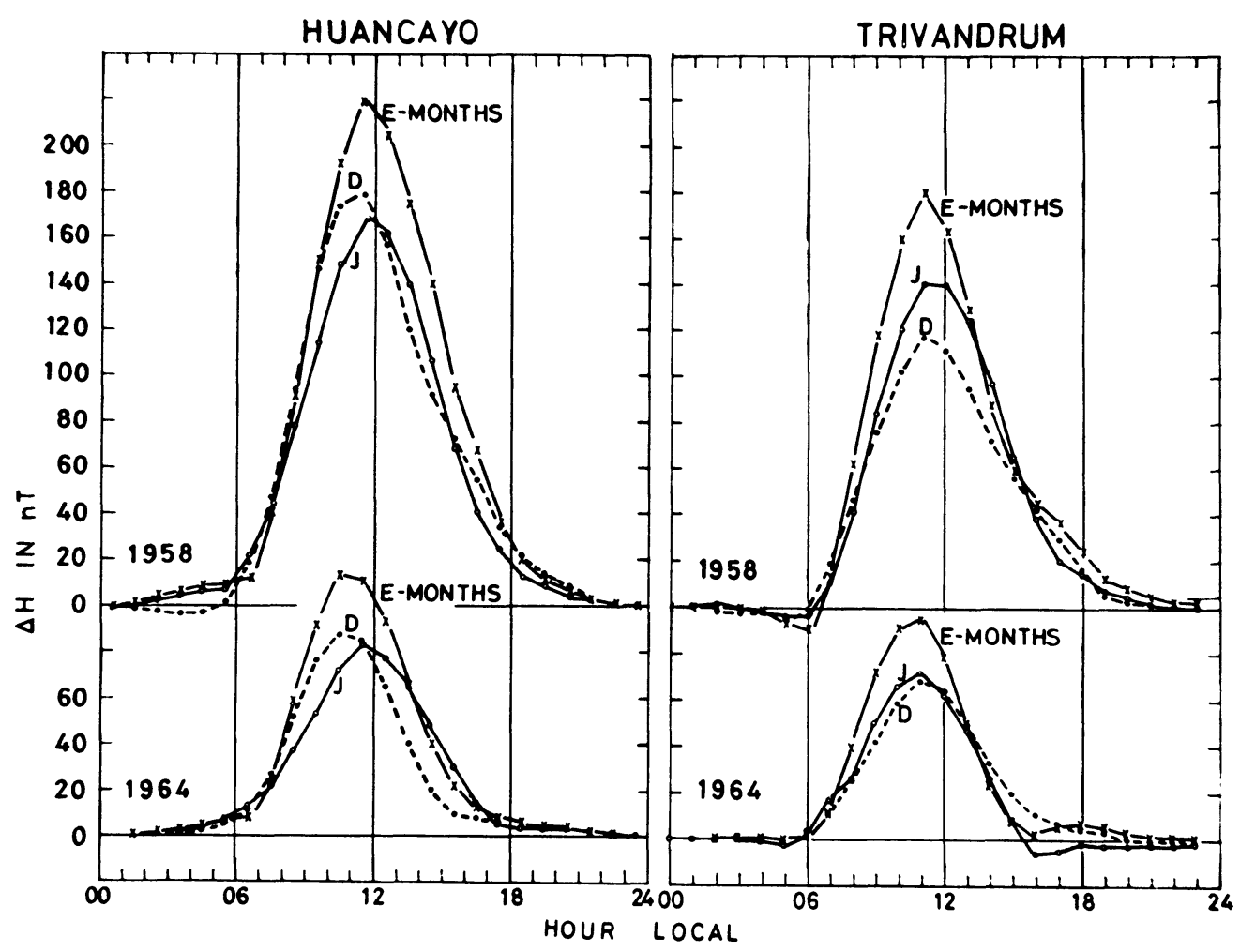

Fig. 1. Seasonal average solar daily variations of $H$ at Huancayo and Trivandrum during low (1964) and high (1958) solar activity years. 
was larger during $\mathrm{J}$ months (local summer) than during the $\mathrm{D}$ months (local winter), and there are definite indication that the time of maximum $\Delta H$ was again earlier during local summer than during the local winter months.

To elucidate the seasonal variation in the time of daily maximum of $\Delta H$, in Fig. 2 are shown the daily variations of $H$ at Huancayo and Trivandrum for hours around midday for each month of the low sunspot year 1964. Referring to the daily variation curves for $H$ at Huancayo, it is very clear that the peak value of $H$ occur earliest (at $1010 \mathrm{LT}$ ) in January, the peak occurs later during succeeding months until in the month of June the peak occurred at $1215 \mathrm{LT}$. During later months, the time of peak value of $H$ occurred earlier in local time. Thus in the American sector, Huancayo, the peak value of $\Delta H$ occurred earliest during local summer and later during the winter months, the time shift being about two hours.
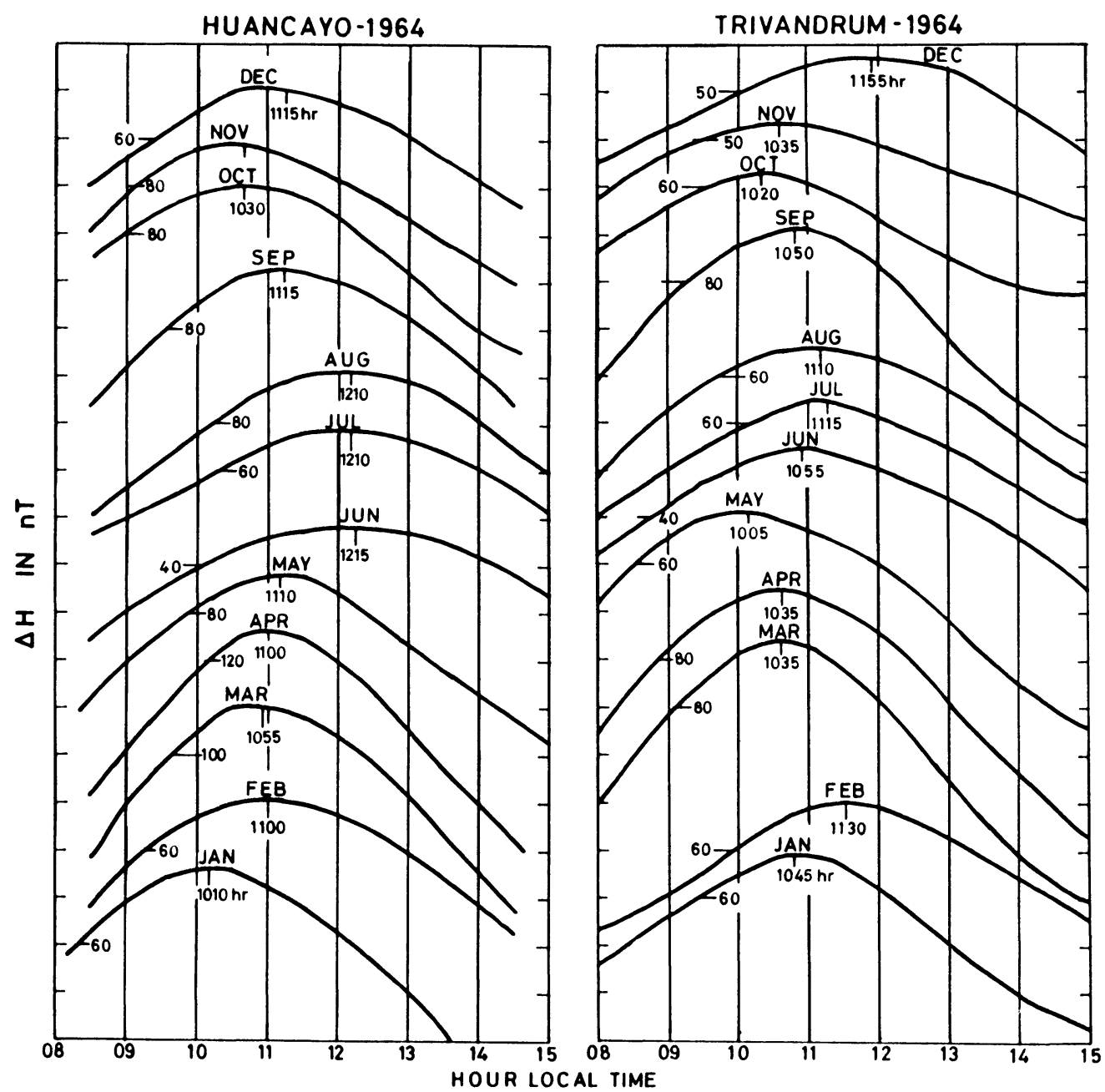

Fig. 2. Solar daily variations of $H$ field at Huancayo and Trivandrum during individual months of 1964 showing the seasonal variation in the time of midday peak of $\Delta H$. 


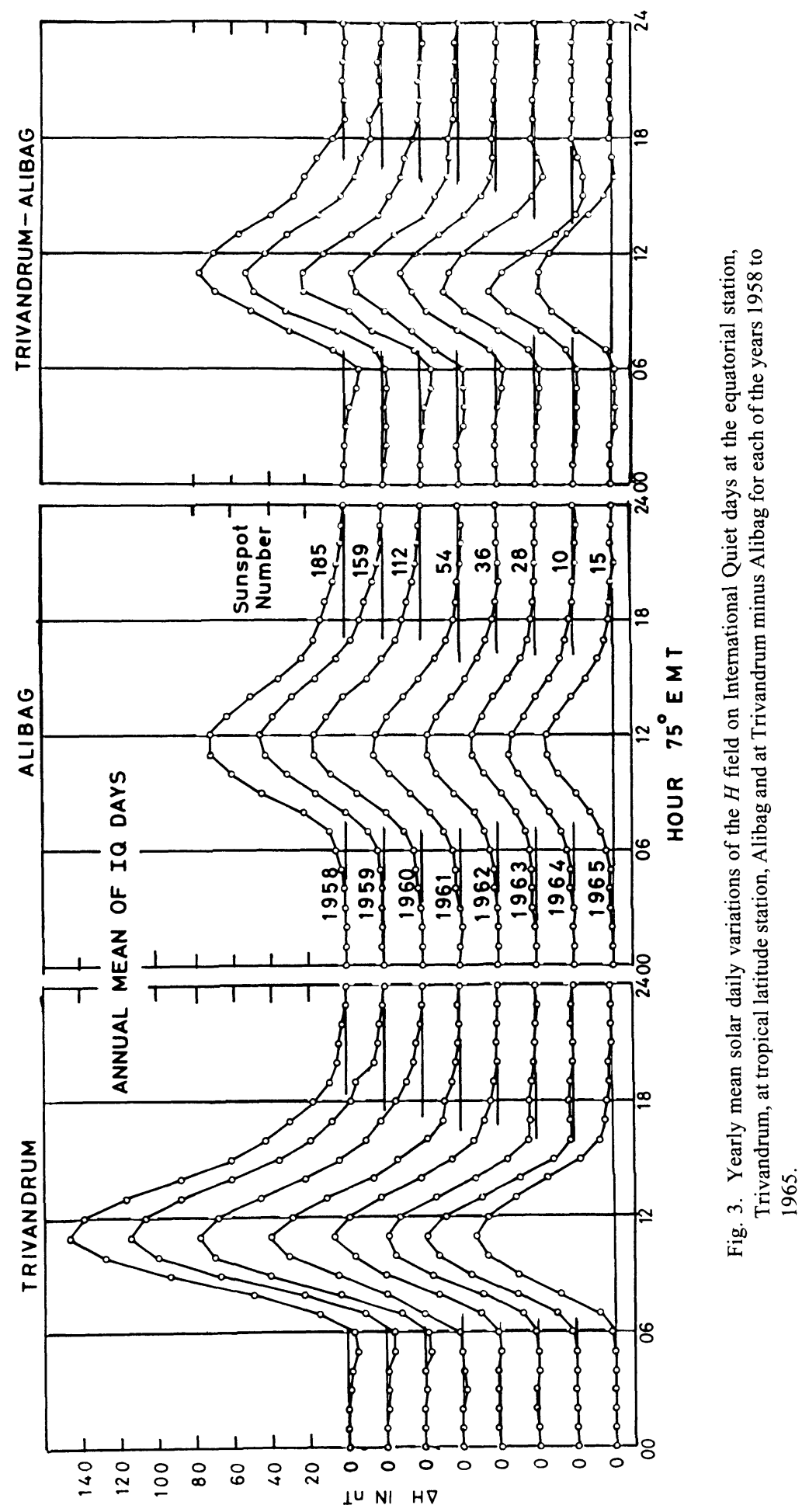


Referring to the curves for Trivandrum, it is seen that the peak of $\Delta H$ occurred earliest during May (1005 LT) and later in December (1155 LT). The month to month change was not so regular as in the case of Huancayo. However, it is easy to conclude that the strength of the electrojet is weaker during local winter than during summer months and the peak occurs about two hours earlier in winter than in summer months.

In Fig. 3 are shown the yearly mean solar quiet day variations for 1958 of $H$ at Trivandrum, at Alibag and $\Delta H$ Trivandrum minus Alibag for each of the years from 1958 to 1965 . The annual mean sunspot numbers are also indicated in the diagram to show the level of solar activity during these years.

During the low sunspot years $1965(R=15), 1964(R=10)$ and $1963(R=28)$, the levels of $\Delta H$ at Trivandrum as well as at Alibag were practically zero throughout the night time hours, $1800 \mathrm{LT}$ to $0600 \mathrm{LT}$. The values of $\Delta H$ (TRD - ABG) remained steadily close to zero throughout the night hours. Actually it attained the zero level sometimes before sunset and remained zero definitely upto $0600 \mathrm{LT}$. $\Delta H$ (TRD - ABG) increased steadily afterwards reached the peak value between 1000-1100 LT and attained negative value during some hours in the afternoon, characteristing the occurrence of counter-electrojet events during the afternoon hours of low sunspot years (PATIL et al., 1990a, b).

With increasing solar activity, the $\Delta H$ value continues above the midnight level upto increasing hours of the night after sunset. During 1958 the $\Delta H$ (TRD - ABG) attains near midnight level only around midnight itself and $\triangle H(\mathrm{TRD}-\mathrm{ABG})$ continues to decrease upto presunrise hours. The negative value of $\Delta H$ are seen during the presunrise hours of high sunspot years both in the variation of $\Delta H$ (TRD) and more clearly in the variation of $\Delta H(\mathrm{TRD}-\mathrm{ABG})$. This feature is consistent with the results of PATIL et al. (1990a, b).

In Fig. 4 are shown the yearly mean solar activity variations of $\Delta H$ (TRD $-\mathrm{ABG}$ ) for each of the years from 1969 to 1985 . The level of solar activity during each of the years are also indicated on the curves by the annual mean sunspot numbers. During the low sunspot years $1973(R=39)$ and $1974(R=34)$, the $\Delta H(\mathrm{TRD}-\mathrm{ABG})$ values were close to zero throughout the night as well as during couple of hours before sunspot, the eastward electrojet current was confined only between 0700 and $1600 \mathrm{LT}$. During the minimum sunspot years $1975(R=16)$, $1976(R=13), 1977(R=28)$ and $1985(R=18)$ the value of $\Delta H(\mathrm{TRD}-\mathrm{ABG})$ showed negative values between 1600-1700 LT due to counter electrojet events. During high sunspot years, the asymmetry of daily variation of $\Delta H$ (TRD - ABG) was very clear with higher values in the afternoon than during the forenoon hours and $\triangle H$ (TRD - ABG) was positive for one or two hours after sunset and showed negative values during presunrise hours.

It is to be noted that the level of $\Delta H(\mathrm{TRD}-\mathrm{ABG})$ was practically constant from $2300 \mathrm{LT}$ to $0300 \mathrm{LT}$ during any period of solar activity. Thus, any of these time period can be taken as the period of no electrojet current and the value of base-level for computing $\Delta H$ during any hour of the day.

Next, we investigate any possible effect of geomagnetic disturbances on the abnormalities in the daily variations of $H$ at Trivandrum and Alibag. In Fig. 5 are shown the solar daily variations of $\Delta H(\mathrm{TRD}-\mathrm{ABG})$ averaged over International Quiet and Disturbed days during different solar epochs, low sunspot years 1962-1964 $(R=25)$, medium sunspot years $1968-$ $1970(R=106)$ and very active solar epoch $1958-1960(R=152)$. It is seen that during low sunspot years 1962-64, $\Delta H$ (TRD - ABG) had reached the night time base level both on IQ or ID days before sunset. However it is important to note that the afternoon counter-electrojet effect was absent on ID days. During the years 1968-70, the evening values of $\Delta H$ (TRD - 
ABG) were higher on disturbed than on quiet days. The continuation of positive $\Delta H$ (TRD $\mathrm{ABG}$ ) after sunset is much more evident on disturbed days of maximum sunspot years 195860 .

Another interesting point to be noted is that the midday values of $\Delta H(\mathrm{TRD}-\mathrm{ABG})$ are consistently smaller on quiet than on disturbed days during any of the solar epoch. It has been shown by direct comparison of magnetic field data and the VHF back scatter doppler shift data that the doppler shift is much better related to $\Delta H$ (TRD - ABG) than to $\Delta H$ (TRD) on quiet or on geomagnetic storm days (RASTOGI and PATIL, 1986). The ionospheric drifts at the equatorial station Thumba are correlated with $\Delta H(\mathrm{TRD}-\mathrm{ABG})$ or $\Delta H(\mathrm{KOD}-\mathrm{ABG})$ rather than with $\Delta H$ (TRD) or $\Delta H$ (KOD) alone (RASTOGI, 1975). The $q$ type of sporadic $\mathrm{E}$ at equatorial stations is also related closely to the difference of $\Delta H$ over the equator minus $\Delta H$ at the station outside the electrojet belt (CHANDRA and RASTOGI, 1974). Thus, it had been

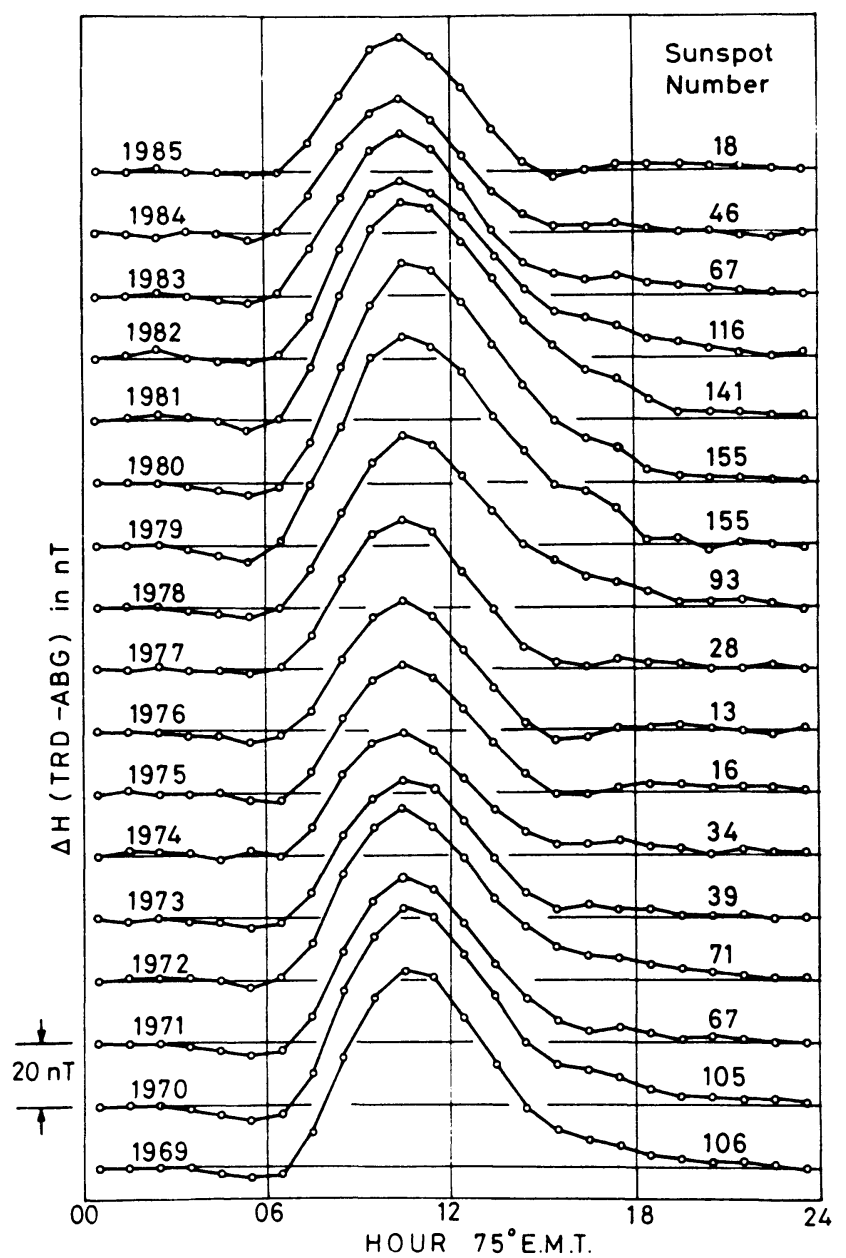

Fig. 4. Yearly mean solar daily variations of $\Delta H$ (TRD - ABG) for each of the years 1965 to 1985 . 


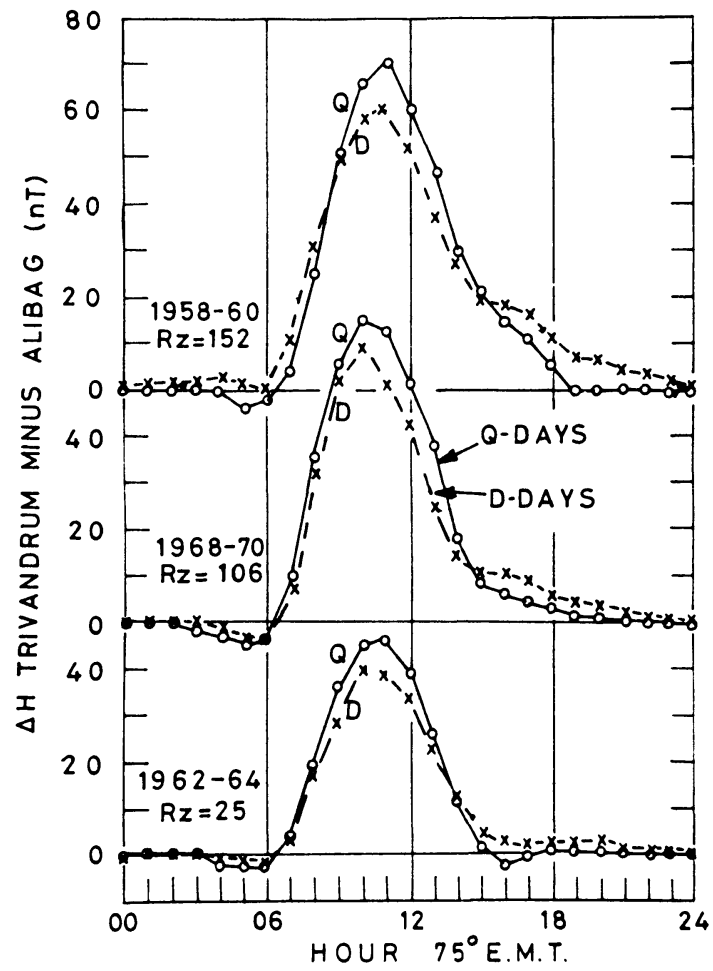

Fig. 5. Solar daily variations of equatorial electrojet current designated by $\Delta H$ at Trivandrum minus $\Delta H$ at Alibag during years of varying solar activity.

concluded that the $\Delta H$ (TRD - $\mathrm{ABG}$ ) very truly depicts the strength of equatorial electrojet current strength. Considering this, the present data confirm that the equatorial electrojet current strength is weaker on disturbed than on quiet days of any of the years with low or high solar activity.

\section{Conclusions}

Classically the equatorial electrojet current had been considered just the enhancement of the global $S q$ currents due to the enhanced electrical conductivities over the magnetic equator. SARABHAI and NAIR (1971) had indicated the effects due to various magnetospheric currents on the ground measurements of $H$ field at the ground level at equatorial latitudes. Using simultaneous, ionospheric drift, magnetometer and ionosonde data at equatorial stations in India, RASTOGI (1975) had shown the equatorial electrojet current is composed of one flowing eastward during the day light hours at $107 \mathrm{~km}$ altitude related to global $S q$ current and another current at $100 \mathrm{~km}$ altitude which may be flowing either eastward or westward. One of the source of ionospheric current over the equator other than related to $S q$ current was identified by RASTOGI and PATEL (1975) to be related to the sudden reversal of the interplanetary magnetic field. Complex vertical structures in the horizontal electric field over the equatorial 
station Thumba have been identified by (REDDY, 1989) using VHF backscatter. The increase of $\Delta H$ at the sudden commencement of geomagnetic storms is explained as the result of the compression of magnetosphere by the pressure of enhanced solar wind following solar eruptions. An increase of electric field in the $E$ region over the magnetic equator at the time of the SSC increase of $\Delta H$ has been inferred from the ionospheric data of HF soundings (RASTOGI, 1976) and VHF scatter soundings (REDDY et al., 1981) signatures of electron clouds in the solar wind has been detected at equatorial latitudes in sympathy with high latitude phenomena (SOMAYAJULU et al., 1985). Thus it has been clear that besides the classical atmospheric dynamo electric fields, the equatorial region is subjected to temporary imposition of electric fields due to numerous events near earth's environment. These modification of equatorial electric fields have direct repurcussions on the plasma density, plasma irregularities and the dynamics of the equatorial ionosphere. A detailed understanding of these modifications of equatorial electric fields should yield to a better understanding of the interaction between equatorial geomagnetism and ionosphere. Simultaneous operations of vertical ionosonde, VHF back scatter radar, the HF doppler radar and the magnetometers at the same location near the magnetic equator would greatly assist understanding the complex phenomena of equatorial ionosphere.

The investigations were started when Prof. Rastogi was Director of Indian Institute of Geomagnetism, Bombay. Grateful thanks are due to Indian Institute of Geomagnetism, Department of Science and Technology, Council of Scientific and Industrial Research and Physical Research Laboratory for support and facilities for conducting these research activities.

\section{REFERENCES}

AKASOFU, S. I. and S. ChAPMAN, The enhancement of the equatorial electrojet during polar magnetic substorms, $J$. Geophys. Res., 68, 2375-2382, 1963.

Chandra, H. and R. G. Rastogi, Geomagnetic storm effects on ionospheric drifts and the equatorial Es over the magnetic equator, Ind. J. Rad. Space Phys., 3, 332-336, 1974.

Kavanagh, L. D., J. W. Freeman, and A. J. Chan, Plasma flow in the magnetosphere, J. Geophys. Res., 73, 5511$5519,1968$.

MEAD, G. D., Deformation of the geomagnetic field by the solar wind, J. Geophys. Res., 69, 1181-1196, 1964.

Olson, W. P., The contribution of magnetospheric current to Sq, Pure Appl. Geophys., 131, 447-462, 1989.

PATIL, A. R., D. R. K. RAO, and R. G. RASTOGI, Equatorial electrojet strength in the Indian and American sectors, Part I. During low solar activity, J. Geomag. Geoelectr., 42, 801-811, 1990a.

Patil, A. R., D. R. K. RaO, and R. G. Rastogi, Equatorial electrojet strength in the Indian and American sectors, Part III. During high solar activity, J. Geomag. Geoelectr., 42, 813-823, 1990 b.

RASTOGI, R. G., On the simultaneous existence of eastward and westward flowing equatorial electrojet current, Proc. Ind. Acad. Sci., 81A, 80-92, 1975.

RAStogi, R. G., Equatorial $E$ region electric field changes associated with a geomagnetic storm sudden commencement, J. Geophys. Res., 81, 687-689, 1976.

RASTOGI, R. G. and K. N. IYER, Quiet day variations of geomagnetic $H$ field at low latitudes, J. Geomag. Geoelectr., 28, 461-479, 1976.

Rastogi, R. G. and V. L. PATEL, Effect of interplanetary magnetic field on ionosphere over the magnetic equator, Prof. Ind. Acad. Sci., 82(4), 121-141, 1975.

Rastogi, R. G. and A. R. PAtil, Complex structure of equatorial electrojet current, Curr. Sci., 55, 433-436, 1986. Reddy, C. A., The equatorial electrojet, Pure Appl. Geophys., 131, 485-508, 1989.

REDDY, C. A., V. V. Somayajulu, and K. S. Viswanathan, Back-scatter radar measurements of storm-time electric field changes in the equatorial electrojet, J. Atmos. Terr. Phys., 49, 193-200, 1981.

SARABHAI, V. and K. N. NAIR, Morphology of geomagnetic field variations and a study of the interplanetary 
magnetic field fluctuations in relation to the daily variations of the geomagnetic field at low latitudes, Cosmic Electrodyn., 2, 3-21, 1971.

SChield, M. A., Pressure balance between solar wind and magnetosphere, J. Geophys. Res., 74, 1275-1286, 1969. Somayajulu, V. V., C. A. Reddy, and K. S. Viswanathan, Simultaneous electric field changes in the equatorial electrojet in phase with polar cusp latitude changes during a magnetic storm, Geophys. Res. Lett., 12, 473-475, 1985. 